\title{
Prenatal and puerperium nutritional care from an integrality perspective in a city of Baixada Santista, São Paulo, Brazil
}

Anna Sylvia de Campos Motta Laporte 1

iD https://orcid.org/0000-0001-9298-5158

Lia Thieme Oikawa Zangirolani 2

https://orcid.org/0000-0002-9966-5701

Maria Angélica Tavares de Medeiros 3

https://orcid.org/0000-0002-8982-7084

\footnotetext{
Instituto de Saúde e Sociedade. Universidade Federal de São Paulo. Campus Baixada Santista. Santos, SP, Brasil

2,3 Departamento de Políticas Públicas e Saúde Coletiva. Instituto de Saúde e Sociedade. Universidade Federal de São Paulo. Universidade Federal de São Paulo. Campus Baixada Santista. Rua Silva Jardim, 136. Vila Mathias. Santos, SP, Brasil. CEP: 11.015-020. E-mail: angelica.medeiros@unifesp.br
}

\begin{abstract}
Objectives: to perform a comparative assessment of the nutritional care process in the prenatal and puerperium periods at a primary care unit in the city of Santos, SP, Brazil before and after the implantation of the Prenatal and Puerperium Nutritional Care Strategy.

Methods: a cross-sectional study was composed of 58 pairs of women and their children, of whom, 30 underwent prenatal care before and 28 of them after the implantation by collecting data from perinatal registrations and children's charts. The care was evaluated by the official National guidelines. The chi-square test was used to compare variables between the pre and post intervention groups.

Results: there was a significant improvement after the nutritional intervention, regarding to height ( $p=0.001)$, registration on pre-pregnancy weight $(p=0.032)$, follow up on Body Mass Index/gestational week $(p=0.001)$, registration on newborn's weight at discharge $(p=0.011)$ and daily weight gain at the first pediatric consultation $(p=0.019)$.

Conclusions: the Prenatal and Puerperal Nutritional Care Strategy contributed to improve maternal-child nutritional care and the data registration on patients'charts, demonstrating the necessity to establish processes/flows and an integral care for this population.

Key words Nutrition policy, Prenatal care, Puerperium, Nutrition in Public health, Primary health care
\end{abstract}




\section{Introduction}

Despite the reduction in maternal and neonatal mortality in Brazil, it is still critical how a large number of young individuals die due to direct obstetric causes related to hypertension, especially eclampsia, and hemorrhagic problems during childbirth. The occurrence of premature births and early neonatal deaths is also a concern. These situations can be improved with nutritional interventions in the prenatal period. 1,2

An adequate, healthy dietary is essential to promote and protect the health of mothers and children. Nutritional disorders, especially overweight and obesity, are common among pregnant women as well as women of childbearing age which can lead to maternal morbidity such as an increase in the prevalence of gestational diabetes and hypertensive diseases. 1,3 To combat this epidemiological problem, the Brazilian Health Ministry established actions and policies to ensure integrality care. 1

As a doctrinal principle of the Sistema Único de Saúde (SUS) (Public Healthcare System) in Brazil, integrality care considers professional healthcare practices in its broadest scope and not only as treating the symptoms, but as the basis of the patients' perception inserted in their social-historical context. ${ }^{4}$ Among these actions, nutritional care is a fundamental component in achieving integrality care for the mother and the baby, understanding the diagnostic and the dietary and nutritional observation by promoting adequate and healthy food, nutritional education and prevention measures. 1,5

In the context of maternal-child health, multidisciplinary work, including the co-responsibility on care and work processes determined by the team, plays an important role in the qualifying actions. 6 The importance of nutritional care has been recognized in studies that reported a large proportion of women with inadequate pre-gestational weight 3,7 as well as deficiencies in diagnostic process and nutritional follow-up ${ }^{8-10}$ and the offering of educational activities and dietary counseling. $8,10,11$

Although several studies have assessed the quality of prenatal care, $8,11-14$ few have addressed the assessment on nutritional care in this life cycle phase. Permanent assessment is necessary and can be achieved by using indicators based on medical registration and perinatal charts. 1 The health information, constitutes from these registration, the raw materials of the decision-making process and the lack of these registration may indicate the absence the procedure, exerting losses in the quality of care. 15
Considering the scarcity of studies that evaluate the nutritional care process and the proposal of the implantation of the Prenatal and Puerperium Nutritional Care Strategy, which is the integration among universities and healthcare services. The aim of the present study was to assess a comparative prenatal and puerperium nutritional care process at a Primary Healthcare Unit in two different moments, before and after an intervention, which consisted in the implantation of this strategy.

\section{Methods}

An evaluative, comparative, cross-sectional study was carried out at a Primary Healthcare Unit in the region of Morros in the city of Santos, which is located on the South coast in the State of São Paulo, Brazil. This study received the approval from the Municipal Secretary of Health in Santos (document number: 32900) and the Human Research Ethics Committee at Universidade Federal de São Paulo (document number: 507.901) and received fundings from the Conselho Nacional de Desenvolvimento Científico e Tecnológico (CNPq) (National Council of Scientific and Technological Development); process number: 486017/2011-7).

The city of Santos presents high maternal and neonatal mortality rates. The most recent rates $(81.9$ deaths of mothers/100,000 livebirths and 9.17 neonatal deaths/1,000 livebirths) surpass the average in the State of São Paulo, 45.5/100,000 and 7.93/1,000 livebirths, respectively. 16

Primary care in Santos involves both Primary Healthcare Units and Family Healthcare Units, these latter ones are formed with minimal teams (physicians, nurses, dentists and health agents). For this present study, a Primary Healthcare Unit was selected due to the actions conducted in 2010, which resulted in the implantation of the Prenatal and Puerperium Nutritional Care Strategy.

The proposal for this strategy arose from the recognition in the necessity to improve dietary and nutritional actions in the prenatal and puerperium periods to ensure integral care for this population. This proposal was approved by the following actions: nutritional interdisciplinary focused on nutritional assessments and follow-ups during pregnancy; mothers and newborns' health surveillance project and breastfeeding encouragement performed by continuous home visits as part of the prenatal care.

The implantation of the Prenatal and Puerperium Nutritional Care Strategy is described in another publication. 17 Briefly, the construction of the 
strategy was preceded in planning meetings between the university and the service to identify the necessities and difficulties to adherence among pregnant women and health professionals, initiate the integrated work and identify issues to be addressed in the educational practices. From this process, it led to the define the flow of actions, an adequate physical space, a patient's chart data updating system, and combine university/service actions and the construction of a protocol addressing socioeconomic issues as well as gestational and health histories. Among the participant health professionals were included: a nutritionist, nurses, nursing assistants, community health agents, a social worker and nutritional interns. ${ }^{17}$

This study was composed of two groups of women who underwent prenatal care at the Primary Healthcare Unit in two different moments: before and after the implantation of the Prenatal and Puerperium Nutritional Care Strategy. The first group was comprised of women who enrolled in the prenatal program in the first semester of 2008 (PRE group) and the second group was comprised of women who enrolled in the prenatal program in the first semester of 2011 (POST group). These periods were chosen to avoid the influence on the outcomes analyzed, as the implantation process occurred during 2010.

After a survey on the registrations in the Primary Healthcare Unit, 42 women were enrolled in the PRE group and 37 were enrolled in the POST group. However, 12 women of the PRE group and nine of the POST group were not included in the study due to referrals in other care services during pregnancy, a change of Primary Healthcare Unit, miscarriage or early neonatal death. Thus, 30 and 28 women were composed in the PRE and POST groups, respectively.

Data collection occurred from June to August 2013 and consisted of a retrospective documental research on women'sperinatal registration and their babies' charts, enabling to assess the compliance of the nutritional care process in the two moments were analyzed (the first semester in 2008 and in 2011) according to the Brazilian Health Ministry guidelines. ${ }^{1}$ However, forms were created based on the variables of interest to characterize the women and assess prenatal/puerperium care process. To assess puerperium period, after the child's birth, we considered the first 42 days, in other hand, based on the pediatric consultation calendar, data were collected only from the first two pediatric consultations.

The assessment of the prenatal and puerperium processes was based on the theoretical reference proposed by Donabedian. 18 According to the author, a good health service assessment system should consider the dimensions of the structure, process and outcome of the services offered, as "good structure increases the likelihood of a good process and a good process increases the likelihood of a good outcome" (p. 1147). Based on direct observations provided by the three years of experience with the service routine, the structure of the Primary Healthcare Unit was considered adequate for to implant the Prenatal and Puerperium Nutritional Care Strategy. This structure and process assessment was the object of another study conducted in the city. 10

Considering the premise that nutritional care is an essential component to achieve integrality maternal-child care and the lack of the processes directed to assess this care, a service assessment model was applied considering the main actions and routines described in the Health Ministry documents, in which the accomplishment is essential in the nutritional care. 10

The following variables were analyzed as: demographic and socioeconomic characteristics (age, income, schooling, ethnicity, marital status, dependence on alcohol, drugs and/or tobacco); obstetric and family history (pregnancy acceptance, number of pregnancies, history of low birthweight and macrosomia); and family history of hypertension and diabetes. These data were obtained from the perinatal registration used in the city. For the variables, as secondary data, the same classification available on the perinatal registration was used from the city rather than adopt the classification established by the Health Ministry.

For data analyses, initially involved simple descriptive analyses for demographic, socioeconomic and obstetric variables, using simple and relative frequencies as well as measures of central tendency (mean) and dispersion (standard deviation -SD). The chi-square test was used to compare the variables considered in the assessment on prenatal/puerperium nutritional care process between the PRE and POST groups. As for the variables were dichotomized as adequate or inadequate, considering the quality criteria defined by the Health Ministry. To be considered adequate, the following had to be fulfilled: minimum criteria established 1 (initiate prenatal care up to $17^{\text {th }}$ week of gestation, performing at least six prenatal consultations, performing a puerperium consultation up to the 42 nd day after childbirth); assessment on pre-gestational nutritional risk (registration on pre-gestational weight and height); assessment and monitoring of 
nutritional status during pregnancy (registration on weight and on the Body Mass Index (BMI) curve per gestational week at each consultation); diagnostic and monitoring on complications associated with nutrition (registration on blood pressure and edema at the consultations, registration on the results of blood exams, glycemia, type I urine, anti-HIV and hepatitis B in the first and $30^{\text {th }}$ gestational weeks); assessment and monitoring on newborn's nutritional status (registration on weight and length at birth, registration on weight and length during first two consultations, calculation on weight gain, and registration on the growth curve proposed by the World Health Organization (WHO, 2006) ${ }^{19}$ at each consultation and registration on breastfeeding pattern).

The fulfillment of the minimum number of consultations officially established was assessed in the present study supposing that this condition is essential to be effective on nutritional care, enabling greater opportunities to perform a combination of health actions that involve severe health prevention, early diagnosis and health promotion. 1

To assess the adequacy of the registration on weight, blood pressure, edema and the BMI graph/gestational week, the ratio was calculated between the number of these registrations on the chart and the number of consultations, which resulted in the following indices: $<0.5=$ inadequate ratio; $\geq 0.5$ to $<0.75=$ intermediate ratio; and $\geq 0.75=$ adequate ratio. Although some studies consider only the total of consultations as cutoff point for adequate, 20 we opted to consider at least $75 \%$ or higher as adequate, since we were assessing a recent implantation in the process of consolidation. For the comparisons among the groups, the adequate category was analyzed separately as well as associated with the intermediate category. The results were considered statistically significant when $p$-value was $<0.05$. All analyses were processed using the Statistical Package for Social Sciences (SPSS, version 16.0).

\section{Results}

Data were collected from 30 medical charts of women in the PRE group and 28 in the POST group. Mean age was 26.2 (SD 6.0) years old. Table 1 displays demographic, socioeconomic and obstetric characteristics of 58 women from their perinatal registration. For some variables, there was a lack of space to register these data, especially the PRE group, due to the use of the old version of the form. These occurrences were identified as NA (not applicable).
The sample was composed predominantly of white women, married or in a stable union, with a complete primary schooling and reported accepting the pregnancy. These variables were similar in both groups. Most women already had one or more children $(63.3 \%$ in the PRE group and $53.6 \%$ in the POST group, respectively). Among these multiparas, less than $4 \%$ of the women in both groups had a history of a newborn weighing more than $4 \mathrm{~kg}$ and less than $15 \%$ had a history of a newborn weighing less than $2.5 \mathrm{~kg}$.

The adequacy of the variables related to the prenatal care process are displayed in Table 2. Regarding to the minimum criteria established by the National Prenatal and Childbirth Humanization Program, prenatal care initiated up to $17^{\text {th }}$ week of gestation and the minimum of six prenatal consultations surpassed $75 \%$ in both groups. The POST group had a lower proportion of adequate in early onset of prenatal care, although the difference was non-significant. The POST group had a lower proportion of adequacy for the variable at least one consultation in the first trimester $(p=0.024)$.

Regarding the variables related to nutritional care, the results in Table 2 demonstrate, although rates for the measurement of pre-gestational weight and height were low in the POST group $(14.3 \%$ and $64.3 \%$, respectively), these measurements were performed more often in this group compared to the PRE group ( $p=0.032$ and $p=0.001$, respectively). No registration on edema was on the perinatal forms in either group.

A statistically significant increase $(p=0.001)$ was found in the registrations on the BMI graph/gestational week when considering the ratio of registrations per number of consultations regarding both the adequate classification $(\geq 0.75)$ and when this classification was added with the intermediate classification $(\geq 0.5)$.

Regarding to the variables related to the puerperium period, no charts were found on seven of the children in the PRE group and one child in the POST group. Thus, data were collected from 23 and 27 children in each groups, respectively. Of this total, $46 \%$ were females and $54 \%$ were males; $86.8 \%$ of the children were born at full term and $10.5 \%$ were born post-term. The males predominated in the PRE group $(60.9 \%)$ and the females predominated in the POST group (51.9\%).

According to the registrations on the perinatal forms, less than $50 \%$ of the women had a puerperium consultation up to the 42 nd days after childbirth. Moreover, under-reporting was observed as high for the variables analyzed: gestational age at 


\section{Table 1}

Distribution of pregnant women according to demographic, socioeconomic and obstetric obtained from perinatal forms in intervention different groups, Santos, SP, Brazil, 2013. ( $N=58)$

\begin{tabular}{|c|c|c|c|c|}
\hline \multirow[t]{2}{*}{ Variables } & \multicolumn{2}{|c|}{ PRE group (30) } & \multicolumn{2}{|c|}{ POST group (28) } \\
\hline & $n$ & $\%$ & $\mathrm{n}$ & $\%$ \\
\hline \multicolumn{5}{|l|}{ Income } \\
\hline$\geq \mathrm{BMMW}$ & 25 & 83.3 & 20 & 71.4 \\
\hline$<$ BMMW & 2 & 6.7 & 7 & 25.0 \\
\hline NR & 3 & 10.0 & 1 & 3.6 \\
\hline \multicolumn{5}{|l|}{ Schooling } \\
\hline Primary school & 19 & 63.3 & 16 & 57.1 \\
\hline High school & 11 & 36.7 & 10 & 35.7 \\
\hline University & 0 & - & 1 & 3.6 \\
\hline NR & 0 & - & 1 & 3.6 \\
\hline \multicolumn{5}{|l|}{ Ethnicity } \\
\hline White & 11 & 36.7 & 15 & 53.6 \\
\hline Mixed race & 0 & - & 3 & 10.7 \\
\hline Asian & 1 & 3.3 & 9 & 32.1 \\
\hline NA & 17 & 56.7 & 0 & - \\
\hline NR & 1 & 3.3 & 1 & 3.6 \\
\hline \multicolumn{5}{|l|}{ Marital status } \\
\hline Married/Stable union & 22 & 73.3 & 24 & 85.7 \\
\hline Single/other & 8 & 26.7 & 3 & 10.7 \\
\hline NR & 0 & - & 1 & 3.6 \\
\hline \multicolumn{5}{|c|}{ Dependence on alcohol/drugs } \\
\hline No & 10 & 33.3 & 28 & 100.0 \\
\hline NA & 20 & 66.7 & 0 & - \\
\hline \multicolumn{5}{|l|}{ Smoking } \\
\hline Yes & 9 & 30.0 & 5 & 17.9 \\
\hline No & 21 & 70.0 & 23 & 82.1 \\
\hline \multicolumn{5}{|l|}{ Pregnancy } \\
\hline Accepted & 19 & 63.3 & 19 & 67.9 \\
\hline Unwanted & 1 & 3.3 & 1 & 3.6 \\
\hline Planned & 10 & 33.3 & 7 & 25 \\
\hline SR & 0 & - & 1 & 3.6 \\
\hline \multicolumn{5}{|l|}{ Primiparity } \\
\hline Yes & 11 & 36.7 & 13 & 46.4 \\
\hline No & 19 & 63.3 & 15 & 53.6 \\
\hline \multicolumn{5}{|l|}{ History of NB $<2.5 \mathrm{Kg}(34)$} \\
\hline Yes & 4 & 13.3 & 4 & 14.3 \\
\hline No & 15 & 50.0 & 10 & 35.7 \\
\hline NR & 0 & - & 1 & 3.6 \\
\hline \multicolumn{5}{|l|}{ History of NB > $4 \mathrm{Kg}(34)$} \\
\hline Yes & 1 & 3.3 & 1 & 3.6 \\
\hline No & 18 & 60.0 & 13 & 46.4 \\
\hline NR & 0 & - & 1 & 3.6 \\
\hline \multicolumn{5}{|c|}{ Family history of hypertension } \\
\hline Yes & 14 & 46.7 & 18 & 64.3 \\
\hline No & 16 & 53.3 & 10 & 35.7 \\
\hline \multicolumn{5}{|c|}{ Family history of diabetes mellitus } \\
\hline Yes & 12 & 40.0 & 14 & 50.0 \\
\hline No & 18 & 60.0 & 14 & 50.0 \\
\hline
\end{tabular}

$\mathrm{BMMW}=$ Brazilian monthly minimum wage; $\mathrm{NR}=$ not registered; $\mathrm{NA}=$ not applicable; $\mathrm{NB}=$ newborn; $\mathrm{SAH}=$ systemic arterial hypertension; $\mathrm{DM}=$ diabetes mellitus. 
Assessment on adequacy in prenatal care process according to the registrations on perinatal forms in intervention different groups. Santos, SP, Brazil, 2013. $(n=58)$

\begin{tabular}{|c|c|c|c|c|c|}
\hline \multirow[t]{2}{*}{ Process } & \multicolumn{2}{|c|}{ PRE group (30) } & \multicolumn{2}{|c|}{ POST group (28) } & \multirow[t]{2}{*}{$p^{*}$} \\
\hline & $\mathrm{n}$ & $\%$ & $\mathrm{n}$ & $\%$ & \\
\hline Onset of prenatal care $<17$ weeks & 26 & 86.7 & 21 & 75 & 0.257 \\
\hline At least six consultations & 24 & 80.0 & 23 & 82.1 & 0.835 \\
\hline At least one consultation in the $1^{\text {st }}$ trimester & 26 & 86.7 & 17 & 60.7 & 0.024 \\
\hline At least two consultations in the $2^{\text {nd }}$ trimester & 27 & 90.0 & 24 & 85.7 & 0.617 \\
\hline At least three consultations in the 3 rd trimester & 22 & 73.3 & 21 & 75.0 & 0.085 \\
\hline Measurement on pre-gestational weight & 0 & - & 4 & 14.3 & 0.032 \\
\hline Measurement on height & 0 & - & 18 & 64.3 & 0.001 \\
\hline \multicolumn{6}{|l|}{ Measurement on weight/consultation } \\
\hline Adequate - ratio $\geq 0.75$ & 29 & 96.7 & 28 & 100.0 & 0.330 \\
\hline \multicolumn{6}{|l|}{ Filling on BMI per week graph/consultation } \\
\hline Adequate - ratio $\geq 0.75$ & 0 & - & 11 & 39.3 & 0.001 \\
\hline Adequate + intermediate - ratio $\geq 0.5$ & 0 & - & 23 & 82.1 & 0.001 \\
\hline \multicolumn{6}{|l|}{ Measurement on blood pressure/consultation } \\
\hline Adequate - ratio $\geq 0.75$ & 30 & 100.0 & 28 & 100.0 & 1.000 \\
\hline Assessment on edema/consultation: ratio $\geq 0.75$ & 0 & - & 0 & - & 1.000 \\
\hline Registration on hemoglobin exam at 1 st consultation & 30 & 100.0 & 27 & 96.4 & 0.296 \\
\hline Registration on hemoglobin exam on the 30th week & 25 & 83.3 & 20 & 71.4 & 0.277 \\
\hline Registration on glucose exam at the 1 st consultation & 29 & 96.7 & 27 & 96.4 & 0.960 \\
\hline Registration on glucose exam on the 30th week & 21 & 70.0 & 16 & 57.1 & 0.309 \\
\hline Registration on urine exam at the 1 st consultation & 30 & 100.0 & 27 & 96.4 & 0.296 \\
\hline Registration on urine exam on the $30^{\text {th }}$ week & 22 & 73.3 & 17 & 60.7 & 0.306 \\
\hline Registration on HIV exam at the 1 st consultation & 28 & 93.3 & 26 & 92.9 & 0.512 \\
\hline Registration on HIV exam on the $30^{\text {th }}$ week & 14 & 46.7 & 15 & 53.6 & 0.463 \\
\hline Registration on hepatitis B exam at the 1 st consultation & 30 & 100 & 27 & 96.4 & 0.296 \\
\hline Registration on hepatitis B exam on the 30 th $^{\text {h }}$ week & 20 & 66.7 & 18 & 64.3 & 0.849 \\
\hline
\end{tabular}

* chi-square test.

birth was observed at $13.3 \%$ and $17.85 \%$ and the type of birth at $13.3 \%$ and $42.8 \%$ in the PRE and POST groups, respectively. A significant increase in the registration on birthweight in the perinatal form was found in the POST group ( $p=0.022)$.

Analyzing the infants' charts, a low proportion of registration on the newborn's weight upon discharge was found in the PRE group (4.3\%), with a significant increase $(p=0.022)$ in the POST group (33.3\%) but the proportion was still considered low. Among the variables of the dimension process regarding the assessment and follow-up on the children's nutritional status in the puerperium period, the proportion of registrations on weight gain during the first two pediatric consultations was low, but was significantly higher during the first consultation compared to the second ( $p=0.019)$. The proportion of filling the weight and length for age curves was low, especially in the POST group (Table 3).

\section{Discussion}

The present findings indicate that the accomplishment of a minimum of six prenatal consultations established by the National Prenatal and Childbirth Humanization Program was higher in comparison to data found in the literature, which reports adequacy rates of up to only $60 \% .8,9,21,22$ A reduction in the proportion of adequacy was found regarding the onset of prenatal care up to the $17^{\text {th }}$ week of gestation in the POST group comparing to the PRE group. This reduction was reflected in the fulfillment of at least one consultation in the first trimester, which was lower in the POST group. Although, this is an important indicator of adequacy in prenatal care, the non-fulfillment of the first consultation in the first trimester was among $30.3 \%$ of the women who did not affect the recommendation of a minimum of six prenatal consultations, for which the rate was higher in the POST group $(82.1 \%)$, even surpassing data described in previous studies, which reported rates 
Assessment of adequacy of puerperium care process according to the registration on perinatal forms and newborn's charts in intervention different groups. Santos, SP, Brazil, 2013. $(n=50)$

\begin{tabular}{|c|c|c|c|c|c|}
\hline \multirow[t]{2}{*}{ Process } & \multicolumn{2}{|c|}{ PRE group (23) } & \multicolumn{2}{|c|}{ POST group (27) } & \multirow[t]{2}{*}{$p^{*}$} \\
\hline & $\mathrm{n}$ & $\%$ & $\mathrm{n}$ & $\%$ & \\
\hline \multicolumn{6}{|l|}{ Registration on perinatal form } \\
\hline First puerperal consultation within 42 days & 11 & 47.8 & 10 & 37.0 & 0.441 \\
\hline Registration on birthweight & 4 & 17.4 & 13 & 48.1 & 0.022 \\
\hline Breastfeeding pattern & 2 & 8.7 & 2 & 7.4 & 0.867 \\
\hline \multicolumn{6}{|l|}{ Registration at the first pediatric consultation } \\
\hline Registration on weight at discharge & 1 & 4.3 & 9 & 33.3 & 0.011 \\
\hline Registration on gestational age & 15 & 62.5 & 23 & 85.2 & 0.099 \\
\hline Birthweight & 20 & 87.0 & 25 & 92.6 & 0.508 \\
\hline Length at birth & 20 & 87.0 & 25 & 92.6 & 0.508 \\
\hline Weight & 21 & 91.3 & 25 & 92.6 & 0.867 \\
\hline Length & 21 & 91.3 & 24 & 88.9 & 0.777 \\
\hline Weight gain & 6 & 26.1 & 16 & 59.3 & 0.019 \\
\hline Breastfeeding pattern & 20 & 87.0 & 25 & 92.6 & 0.508 \\
\hline \multicolumn{6}{|l|}{ Registration on the second pediatric consultation } \\
\hline Weight & 19 & 88.6 & 24 & 88.9 & 0.524 \\
\hline Length & 18 & 78.3 & 22 & 81.5 & 0.777 \\
\hline Weight gain & 7 & 30.4 & 13 & 48.1 & 0.203 \\
\hline Breastfeeding pattern & 20 & 87.0 & 23 & 85.2 & 0.857 \\
\hline Presence of weight and length/age curve (WHO, 2006) & 16 & 69.6 & 1 & 3.7 & 0.001 \\
\hline Filling on weight and length/age curve (WHO, 2006) & 15 & 65.2 & 1 & 3.7 & 0.001 \\
\hline
\end{tabular}

WHO $=$ World Health Organization.

ranging from $66 \%$ to $79 \%$ of adequacy. $8,11,21,22$

Regarding to the nutritional care process during the prenatal period, compliance was high in both groups regarding the measurement on weight and blood pressure, both expressed on Table 2 from the variable of ratio registered on weight per consultations and registrations on blood pressure per consultations, as reported in previous studies. $8,9,11,14,22$ However, the significant increase in the registration on height, pre-gestational weight and follow-up on the BMI graph/gestational week between the PRE and POST groups suggests the incorporation of these actions by the healthcare team after the intervention, considering the complete absence of these registrations in the PRE group.

Pre-gestational weight is an important indicator of nutritional risk and the prediction of weight gain during pregnancy. ${ }^{2}$ This variable was only registered in the POST group and only on $14.3 \%$ of the perinatal forms. This rate is much lower than that described by Niquini et al., ${ }^{9}$ who conducted the only recent study considering the registration on pregestational weight and height in the assessment of the prenatal nutritional care process in seven Family Health Units in the city of Rio de Janeiro, reporting a $65.9 \%$ of adequacy rate. Regarding to the registration on the height, the present rate of $64.3 \%$ surpassed what was described by Niquini et al. 9 $(57.7 \%)$.

The incomplete data on pre-gestational weight and height found in Niquini et al. 9 study and the present study, especially in the PRE intervention group, draws attention to the under-valuing of the nutritional follow-up on pregnant women. Without these data, it is impossible to perform an assessment of the initial nutritional status, estimate gestational weight gain and assess nutritional status throughout the pregnancy through the filling of the BMI graph/gestational week. Such data were not even considered in other recent studies assessing the prenatal care process. $8,22,23$

Although only $39 \%$ of the perinatal forms analyzed in the POST group had a ratio of registrations on the BMI per gestational week/consultation classified as adequate $(\geq 0.75)$, this figure surpasses data described in recent studies. Analyzing 360 medical charts of pregnant women at The Public Healthcare services in the city of Vitória (the State of Espírito Santo), Pogliani et al.11 found no registrations on maternal height in nearly $50 \%$ of the 
charts and the authors did not consider the importance of filling the BMI graph/gestational week. Niquini et al. ${ }^{9}$ found an absence of this registration among $90.7 \%$ of the pregnant women assessed and found only a $3.1 \%$ adequacy rate regarding the ratio of registrations per number of consultations $\geq 0.75$.

When the adequate and intermediate categories were combined (ratio of registrations per number of consultations $>0.5$ ), the adequacy rate was $82.1 \%$ in the POST group. As there were no such registrations at all on the perinatal forms in the PRE group, this result suggests that the implantation of the Prenatal and Puerperium Nutritional Care Strategy led to a gradual and significant incorporation of this important indicator on the nutritional care process in the prenatal period. In a descriptive study conducted at a Primary Healthcare Unit in a region of high social vulnerability in the city of Santos, Siqueira et al.20 found a low proportion of adequacy in the nutritional follow-up of 366 pregnant women, $99.7 \%$ of whom had no registration on the BMI graph/gestational week and the remaining $0.3 \%$ had only intermediate adequacy (ratio of registrations per number of consultations $\geq 0.5$ ). A study conducted by the same group of researchers also reported low adequacy for this variable, as only around $50 \%$ of the administrators reported filling the BMI graph /gestational week. 10

The registrations on the laboratory exams had higher adequacy rates for the first amount of exams solicited during the first prenatal consultations. The findings of the present study were proportionally higher compared to those reported by other authors, $8,11,20$ with the exception on the HIV exam at the $30^{\text {th }}$ week of gestation, for which the lowest adequacy rate was found. The reduction in the rate between the first and second amount of exams has also been described in recent studies. $8,11,24$ Since the implantation of the National Prenatal and Childbirth Humanization Program in Brazil, this deficiency was pointed out by Serruya et al.25 in a study assessing the program. The fulfillment of this recommendation is essential to the diagnosis of the main gestational conditions related to high maternal and neonatal mortality rates and undesirable neonatal outcomes, including sexually transmitted diseases. ${ }^{1}$ The failure to perform these exams reveals deficiencies in the surveillance process and missed opportunities for intervention.

Regarding to the puerperium period, the results of the assessment on the nutritional care process registered on the perinatal forms reveal lower proportions of registrations on the children's charts. The low proportion of adequacy regarding a puer- perium consultation up to the first $42^{\text {nd }}$ days after childbirth in both groups reveals the fragmentation of maternal-child healthcare after the occurrence of childbirth, when maternal health is separated from the infant's health. This fragmentation, expressed by the low adequacy rate of consultations on the puerperium period, constitutes on the obstacle to the consolidation of maternal-child line on care by impeding the integral assessment of the mother and the establishment of conduct to protect her health, such as the prescription of supplements through to 3 rd postpartum month and the support on breastfeeding.

Birthweight is an important indicator and a significant increase in registering this variable on the perinatal form was found in the POST group, although the proportion of adequacy was still less than $50 \%$. In contrast, the adequacy of the registration on birthweight on children's charts were high in both groups. These results suggest that pediatricians should place more value on the nutritional surveillance on newborns. The absence of these registrations on the perinatal forms can exert a negative impact on the communication among the health professionals involved in puerperium care, consequently compromising the quality of the multidisciplinary, multi-professional work. The perinatal form is a data collection instrument for use of health professionals and should contain all the main data from the follow-up on the pregnancy, the childbirth, the newborn's and the puerperium period. 1

Multidisciplinary work goes beyond the flow and fulfillment of protocols and involves co-responsibility in care and the construction of the dialogic work processes. ${ }^{6}$ As the setting in the present study is a traditional Primary Healthcare Unit, there is a need for greater attention to be given to the fragmentation of care among the specialties and the qualification of the multidisciplinary team to ensure integrality care.

High proportions of adequacy were found regarding the anthropometric registrations during the first two pediatric consultations. Moreover, a significant increase was found on the calculation of a daily weight gain during the first consultation in the POST group, although the adequacy rate was still considered low. The investigation of monitoring risk criteria among newborns in the puerperium period is a precept of the official agenda of commitments to integral child health.1,26 Newborn's weight upon discharge was little registered by the health team and this variable is required for calculating the daily weight gain in the puerperium period, constituting a sensitive indicator of growth and development in 
this period. 26

The worst result was found for filling data on the curves recommended by the WHO, with a significant reduction in the POST group. However, the curve of the US National Center for Health Statistics (NCHS/1977), which was previously used, was duly filled in $77 \%$ of the charts in the POST group. This printed curve was provided by the pharmaceutical industry, which could be considered a conflict of interest in public-private relations, since, according to national childcare, dietary and nutritional policies, updated growth curves should be used following WHO recommendations.

Despite the high proportion of adequacy regarding the minimum criteria established by the National Prenatal and Childbirth Humanization Program, the maternal-child health situation in the city is alarming, with high maternal and neonatal mortalities that are above the average in the State of São Paulo. 16

Regardless of the growth in prenatal coverage, 3 deficiencies have been found in the care offered by health services in both number and content of consultations.27 In the National Prenatal and Childbirth Humanization Program, beyond the minimum criteria assessed in the present study, there is a need to establish procedures and practices that ensure follow-up and promote the link between prenatal care and the moment of childbirth. 25

The first 1,000 days of life are considered the window of opportunity for adequate care on growth and development. Health and nutritional care for the mother during the nine months of pregnancy and the investment on exclusive breastfeeding in the first six months, make the first 500 days of life the most important to the health of an individual.28

The importance of these actions was highlighted in Zampieri and Erdman study, ${ }^{29}$ who conducted interviews with pregnant women and health professionals and found that educational activities and home visits were actions considered to be humanizing by the pregnant women.

The strategy implanted in 201017 certainlyneeds to be improved, especially in regards to healthcare for women in the puerperium period and their registrations. There are also necessities for greater attention directed at the assessment of pre-gestational nutritional status, the assessment on edema and the follow-up of child growth and development using the curves proposed by WHO, which were little registration on the perinatal forms. One of the limitations of the present study is the lack of methods that enable a qualitatively more in-depth assessment on nutritional care process based on the implanted strategy.

The underreporting of data on the perinatal forms and children's charts also limited the analysis of this process, which is in agreement with comments by Vasconcelos et al. ${ }^{30}$ regarding the difficulties on health information systems. Although the absence of the procedure cannot be stated because there is no registration of it, this lack of registration is a serious deficiency in the process, as it interferes with access to data on the patients' charts and communication among the health professionals involved. Moreover, the perinatal form represents the link between prenatal care and the moment of childbirth, which is most often performed by health professionals that did not accompany the mother's prenatal care.

One of the strengths of this study was to demonstrate significantly favorable findings regarding nutritional care between the PRE and POST groups. Thus, health actions can have a positive impact on maternal-child health. Besides the quality of the procedures performed, the goal of such actions should be integral care. The Prenatal and Puerperium Nutritional Care Strategy adopted multidisciplinary care through the comprehensive actions of the health professionals and the improvement of data registration on the patient's charts, demonstrated by the high ratio of adequacy of the registration in the POST group. The scarcity of studies assessing the nutritional care process in the puerperium period considering the mother-child dyad, this is a pioneering, evaluative, cross-sectional study that can assist future research on this issue.

The Prenatal and Puerperium Nutritional Care Strategy assessed herein, in accordance with the National Food and Nutrition Policy guidelines ${ }^{5}$ and from the standpoint of the maternal-child health situation in the city of Santos, paves the way for expansion to other local health units and other Brazilian cities, demonstrating the necessity to establish flows and processes for maternal-child nutritional care. However, the management on nutritional care requires constant assessment and investment, given the influence of the context and the strategic role of administrators and health teams to implement actions.

Therefore, it is necessary to invest in participative work processes that lead to the incorporation of these actions by health professionals. For such, partnerships among universities and healthcare services are key to adopt permanent health education with the aim of strengthening multidisciplinary teams and ensuring integrality care. Moreover, to establish a consistent prenatal/puerperium care policy requires 
permanent education through periodic training of health teams. ${ }^{1}$

\section{Authors' contribution}

Laporte ASCM and Medeiros MMAT contributed to the conception of the study, analysis and discussion of the results and the writing of the manuscript.
Zangirolani LTO performed analysis and discussion of the results. All authors approved the final version of the article.

\section{References}

1. Brasil. Ministério da Saúde. Secretaria de Atenção à Saúde. Departamento de Atenção Básica. Brasil. Atenção ao prénatal de baixo risco. Brasília, DF; 2012. 318 p. Available from:

http://bvsms.saude.gov.br/bvs/publicacoes/cadernos_atenca o_basica_32_prenatal.pdf

2. Lansky S, Friche AAF, Silva AAM, Campos D, Bittencourt SDA, Carvalho ML, Frias PG, Cavalcante RS, Cunha AJLA. Pesquisa Nascer no Brasil: perfil da mortalidade neonatal e avaliação da assistência à gestante e ao recémnascido. Cad Saúde Pública. 2014; 30 (Supl.): S192-S207.

3. Brasil. Ministério da Saúde. Pesquisa Nacional de Demografia e Saúde da Criança e da Mulher: PNDS 2006. São Paulo: CEBRAP. 2009. 300 p.

4. Neves JA, Zangirolani LTO, Medeiros MAT. Evaluation of nutritional care of overweight adults from the perspective of comprehensive health care. Rev Nutr. 2017; 30 (4): 51124

5. Brasil. Ministério da Saúde. Secretaria de Atenção à Saúde. Departamento de Atenção Básica. Brasil. Política Nacional de Alimentação e Nutrição. Brasília, DF ; 2012. 84 p.

6. Cunha GT, Campos GWS. Apoio Matricial e Atenção Primária em Saúde. Saúde Soc. 2011; 20 (4): 961-70.

7. Teixeira CSS, Cabral ACV. Avaliação de gestantes sob acompanhamento em serviços de pré-natal distintos: a região Metropolitana e o ambiente rural. Rev Bras Ginecol Obs. 2016; 38 (1): 27-34

8. Carvalho RAS, Santos VS, Melo CM, Gurgel RQ, Oliveira CCC. Avaliação da adequação do cuidado pré-natal segundo a renda familiar em Aracaju, 2011. Epidemiol Serv Saúde. 2016; 25 (2): 271-80.

9. Niquini RP, Bittencourt SA, Lacerda EMDA, Saunders C, Leal MDC. Avaliação do processo da assistência nutricional no pré-natal em sete unidades de saúde da família do Município do Rio de Janeiro. Ciên Saúde Coletiva. 2012; 17 (10): 2805-16.

10. Laporte-Pinfildi, AS de C; Zangirolani L, Spina N, Martins $\mathrm{P}$, Medeiros MAT. Atenção nutricional no pré-natal e no puerpério: percepção dos gestores da Atenção Básica à Saúde. Rev Nutr. 2016; 29 (1): 109-23.

11. Polgliani RBS, Leal MC, Amorim MHC, Zandonade E, Neto ETS. Adequação do processo de assistência pré-natal segundo critérios do Programa de Humanização do Prénatal e Nascimento e da Organização Mundial de Saúde.
Ciênc Saúde Coletiva. 2014: 19 (7): 1999-2010

12. Tomasi E, Fernades PAA, Fischer T, Siqueira FCV, Silveira DS, Thumé E, Duro SMS, Saes MO, Nunes BP, Fassa AG, Facchini LA. Qualidade da atenção pré-natal na rede básica de saúde do Brasil: indicadores e desigualdades sociais. Cad Saúde Pública. 2017; 33 (3): e00195815.

13. Guimarães WSG, Parente RCP, Guimarães TLF, Garnelo L. Acesso e qualidade da atenção pré-natal na Estratégia Saúde da Família: infraestrutura, cuidado e gestão. Cad Saúde Pública. 2018; 34 (5): e00110417

14. Vettore MV, Dias M, Vettore MV, Leal MC. Avaliação da qualidade da atenção pré-natal dentre gestantes com e sem história de prematuridade no Sistema Único de Saúde no Rio de Janeiro, Brasil. Rev Bras Saúde Mater Infant. 2013; 13 (2): $89-100$

15. Santos MMADS, Baião MR, Barros DC De, Pinto ADA, Pedrosa PLM, Saunders C. Estado nutricional pré-gestacional, ganho de peso materno, condições da assistência pré-natal e desfechos perinatais adversos entre puérperas adolescentes. Rev Bras Epidemiol. 2012; 15 (1): 143-4.

16. SEADE (Fundação Sistema Estadual de Análise de Dados) [Internet]. Sistema de Iformações dos municípios paulistas. 2012 [cited 2014 Jun 11]. Available from: http://produtos.seade.gov.br/produtos/perfil/perfilMunEsta do.php

17. Laporte-Pinfildi ASC, Medeiros MAT. Nutritional care during prenatal and postpartum periods: A report of experiences in a city on São Paulo's coast. Rev Nutr. 2016; 29 (6): 947-61

18. Donabedian A. The quality of care. How can it be assessed? 1988. Arch Pathol Lab Med. 1997; 121 (11): 1145-50.

19. Multicentre WHO, Reference G, Group S. WHO Child Growth Standards based on length/height, weight and age. Acta Paediatr. 2006; 450 (Suppl.): 76-85.

20. Siqueira CVC. Assistência Pré-natal em uma Unidade Básica de Saúde do Município de Santos. 2011.

21. Domingues RMSM, Leal M do C, Hartz ZM de A, Dias MAB, Vettore MV. Access to and utilization of prenatal care services in the Unified Health System of the city of Rio de Janeiro, Brazil. Rev Bras Epidemiol. 2013; 16 (4): 95365

22. Bernardes ACF, da Silva RA, Coimbra LC, Alves MTSSDB, Queiroz RCDS, Batista RFL, Bettiol H, Barbieri 
MA, Silva AA. Inadequate prenatal care utilization and associated factors in São Luís, Brazil. BMC Pregnancy Childbirth. 2014; 14: 266. Available from: http://www.pubmedcentral.nih.gov/articlerender.fcgi?artid= 4133632\& tool $=$ pmcentrez\&rendertype $=$ abstract

23. Silva EP Da, Lima RT De, Ferreira NLS, Costa MJDCE. Pré-natal na atenção primária do município de João PessoaPB: caracterização de serviços e usuárias. Rev Bras Saúde Matern Infant. 2013; 13 (1): 29-37.

24. Corrêa MD, Tsunechiro MA, Lima MOP, Bonadio IC. Avaliação da assistência pré-natal em unidade com estratágia saúde da família. Rev Esc Enferm USP. 2014; 48 (Esp): 24-32.

25. Serruya SJ, Cecatti JG, Lago T di G do. O Programa de Humanização no Pré-natal e Nascimento do Ministério da Saúde no Brasil: resultados iniciais. Cad Saúde Pública. 2004; 20 (5): 1281-9.

26. Brasil. Ministério da Saúde. Saúde da Criança: Crescimento e Desenvolvimento [Internet]. Brasil. Ministério da Saúde. Departamento de Atenção Básica. 2012. 272 p. Available from:

http://189.28.128.100/dab/docs/publicacoes/cadernos_ab/c aderno_33.pdf
27. Gonçalves CV, Cesar JA, Mendozasassi RA. Qualidade e eqüidade na assistência à gestante: um estudo de base populacional no Sul do Brasil. Cad Saúde Pública. 2009; 25 (11): 2507-16.

28. Mason JB, Shrimpton R, Saldanha LS, Ramakrishnan U, Victora CG, Girard AW, McFarland DA, Martorell R. The first 500 days of life: policies to support maternal nutrition. Glob Health Action. 2014; 7: 23623. Available from: http://www.pubmedcentral.nih.gov/articlerender.fcgi?artid=4049132\&tool=pmcentrez\&rendertype $=$ abstract

29. Zampieri M de FM, Erdmann AL. Cuidado humanizado no prénatal: um olhar para além das divergências e convergências. Rev Bras Saúde Matern Infant. 2010; 10 (3): 359-67.

30. Vasconcellos MM, Gribel EB, Moraes IHS De. Registros em saúde : avaliação da qualidade do prontuário do paciente na atenção básica, Rio de Janeiro, Brasil Health records : evaluation of patient health charts in primary care, Rio de Janeiro, Brazil. Cad Saúde Pública. 2008; 24 (Supl. 1): 173-82.

Received on August 17, 2018

Final version presented on September 10, 2019

Approved on December 23, 2019 